\title{
Evaluation of three methods to measure anti- Brucella IgM antibodies and interference of IgA in the interpretation of mercaptan-based tests
}

\author{
T. MARRODAN*, R. NENOVA-POLIAKOVA*\|, M. RUBIO*, J. ARIZA†, E. CLAVIJO‡, H. L. SMITS§ \\ and R. DIAZ* \\ * Departamento de Microbiología, Servicio de Microbiología Clínica, Universidad de Navarra, Pamplona Spain, \\ $\uparrow$ Servicio de Enfermedades Infecciosas, Hospital de Bellvitge, Barcelona, Spain, $\ddagger$ Servicio de Microbiología, \\ Hospital Virgen de la Victoria, Málaga, Spain and §Department of Biomedical Research, Royal Tropical \\ Institute, Amsterdam, The Netherlands
}

\begin{abstract}
The results of a dipstick assay for the detection of immunoglobulin M (IgM) to Brucella smooth lipopolysaccharide (S-LPS) correlated with those of an enzyme-linked immunosorbent assay (ELISA) for IgM and of the serum agglutination test (SAT) performed with and without dithiothreitol. Two sera which were dithiothreitol-sensitive and were dipstick negative were shown to contain specific IgA. The dipstick assay is recommended as a simple method for detecting specific IgM antibodies in acute-phase brucellosis patients.
\end{abstract}

\section{Introduction}

Human brucellosis is an infectious disease of worldwide importance. Due to the extraordinary variety of manifestations of this disease, its diagnosis cannot be made solely on clinical grounds and it is always essential to perform bacteriological and serological tests. IgM antibodies to the smooth lipopolysaccharide (S-LPS) predominate in the first days of infection, after which there is a switch to IgG isotype synthesis in individuals who have not received treatment [1]. Consequently, the evaluation of Brucella-specific IgM and IgG antibodies allows discrimination between patients with acute or recent brucellosis and those who have undergone a long infectious process before diagnosis. Discrimination of both classes of antibodies cannot be achieved in the conventional tests for brucellosis, i.e., the Rose Bengal (RB), serum agglutination and complement fixation tests, because although $\operatorname{IgM}$ antibodies specific to the S-LPS are efficient agglutinins, IgG antibodies can behave as either agglutinating or non-agglutinating (incomplete) antibodies and both classes are active in the comple-

Received 28 July 2000; revised version accepted 4 Jan. 2001.

Corresponding author: Dr R. Diaz (e-mail: rdiaz@unav.es). |Present address: National Center of Infectious and Parasitic Diseases, 44A General Stoletov BLD, BG-1233, Sofia, Bulgaria. ment fixation test [2-6]. Thus, complementary tests such as the indirect enzyme-linked immunosorbent assay (ELISA) with S-LPS and anti-IgM and anti-IgG conjugates are used [7]. A different strategy is to use antigens other than the S-LPS, as it has been shown that antibodies to Brucella soluble proteins (SP) develop after the first weeks of infection [2, 8, 9]. Recently, Smits and co-workers [10] described a dipstick assay for the detection of $\operatorname{IgM}$ antibodies specific to Brucella S-LPS which could also be used as a complementary test to evaluate the stage of evolution of the infection. The aim of the present study was to gain a better understanding of the significance of this test in comparison with other tests in current use.

\section{Materials and methods}

Study design and sera

Seven different serological tests - RB; serum microagglutination test (SAT); SAT in the presence of dithiothreitol (SAT-DTT); IgM, IgG and IgA ELISA; counterimmuno-electrophoresis (CIEP) with SP; double-gel immunodiffusion (DGG) with S-LPS; and the IgM dipstick assay - were applied to 62 serum samples from patients with brucellosis taken at the time of hospitalisation, 35 sera from normal healthy donors (including 10 rich in rheumatoid factor) and follow-up samples from 10 treated patients without relapse and from 3 patients with relapse (a minimum of 6 samples per patient). To investigate the role of $\operatorname{IgA}$ in the SAT a 
further 75 sera from brucellosis patients were tested in SAT, SAT-DTT, ELISA and the IgM dipstick assay. The diagnosis was made on the basis of bacteriological or serological and clinical evidence combined.

\section{Serological tests}

The RB agglutination test was performed as described by Morgan et al. [11] with the antigen produced at the Central Veterinary Laboratory (Weybridge, Surrey).

The SAT (equivalent to the conventional tube serum agglutination) was performed by making two-fold serial dilutions from 1 in 20 to 1 in 20480 of the serum samples in $50 \mu \mathrm{l}$ of phosphate-buffered saline (PBS), $\mathrm{pH} \mathrm{7.2,} \mathrm{in} \mathrm{ordinary} \mathrm{96-well} \mathrm{microtitration-type} \mathrm{poly-}$ styrene plates [12]. An equal volume of a 1 in 70 dilution of the ring milk test antigen (Central Veterinary Laboratory, Weybridge) was added to each dilution, and the plates were incubated overnight at room temperature. The SAT-DTT was performed in the same manner except that the serum dilutions were prepared in PBS containing 0.01 M DTT. To determine the role of IgA antibodies in SAT, selected sera were treated with rabbit anti-human $\operatorname{IgA}, \operatorname{IgM}$ or $\operatorname{IgG}$ (Operon, Zaragoza, Spain) to remove immune classspecific antibodies. To this end, $10-\mu 1$ volumes of serum were mixed with $90 \mu \mathrm{l}$ of the rabbit antibody and incubated for $2 \mathrm{~h}$ at $37^{\circ} \mathrm{C}$. The immunoprecipitates were sedimented by centrifugation and removal of the corresponding immunoglobulin was demonstrated by testing the supernates by immunodiffusion with the specific antiserum. The IgA1 subclass antibodies were purified from $0.1 \mathrm{ml}$ of serum by affinity chromatography on jacaline-agarose (Pierce, Rockford, IL, USA), according to the specifications of the manufacturer, and concentrated by ultra-dialysis to the original volume. The amount of $\operatorname{IgA}$ and the purity of the concentrate were assessed by radial immunodiffusion in the Mancini test with commercial plates (Kallestad Diagnostics, Austin, TX, USA) and the serological activity in SAT was verified by removal of antibody with rabbit sera to $\operatorname{IgM}$, IgG and IgA demonstrated double-gel diffusion with these same antisera.

The DGD and CIEP were performed as described previously [2]. The antigens employed in DGD and CIEP were, respectively, LPS extracted from $B$. melitensis $16 \mathrm{M}$ and SP prepared from the rough strain
B. melitensis 115 . The methods of antigen extraction have been described previously [2].

The dipstick assay was performed as described previously [10] by mixing $5 \mu \mathrm{l}$ of serum in the appropriate diluent-developing system ( 1 in 50 serum dilution) and incubating the strip coated with the antigen for $3 \mathrm{~h}$ at $37^{\circ} \mathrm{C}$. The results were rated negative when no staining of the antigen band was observed or from $1+$ to $4+$ according to the staining intensity of the antigen by comparison with a coloured reference strip.

The ELISA for the detection of $\operatorname{IgM}, \operatorname{IgG}$ and $\operatorname{IgA}$ antibodies specific for the S-LPS was performed as described by Ariza et al. [13], except that IgG was detected with peroxidase-recombinant protein G (Pierce) [14] instead of a polyclonal anti-IgG antibody. The protein $\mathrm{G}$ was used at an optimal concentration of $0.2 \mu \mathrm{g} / \mathrm{ml}$ in $10 \mathrm{mM}$ PBS (pH 7.2)-Tween $0.2 \%$ (PBSTween) that had been determined previously by means of a panel of positive and negative control sera.

\section{Results and discussion}

The 62 serum samples from patients with brucellosis were positive in the RB test. A positive result in the dipstick assay was obtained for 44 samples and a negative result for 18 samples. The staining intensity of the positive samples was rated $1+$ for one sample, $2+$ for 11 samples, 3+ for 16 samples and $4+$ for 16 samples. The 35 negative control sera were negative in both tests.

The mean SAT titre for the 44 dipstick-positive sera was 2560, a value three dilution steps higher than the mean titres calculated for the 18 dipstick-negative samples (Table 1). The differences between the SAT titres of these two groups were statistically significant $(\mathrm{p}<0.0001$, Mann-Witney $U$ test $)$. DTT caused a significant reduction in the SAT titre $(\mathrm{p}<0.0001)$ only in the group of dipstick-positive sera (Table 1). The difference between SAT-DTT titres of dipstick-positive and -negative samples was not significant $(\mathrm{p}>0.05)$ (Table 1). Sera with a positive dipstick result had IgM ELISA titres $\geqslant 320$ (the highest titre was 10240 ). In contrast, the titres in the IgM ELISA were $\leqslant 160$ (Table 1) for all dipstick-negative sera. The mean IgM ELISA titre for the 44 dipstick-positive samples was 2560, a

Table 1. Correlation of SAT, SAT-DTT and ELISA with the dipstick assay for the detection of Brucella-specific IgM antibodies

\begin{tabular}{lccl}
\hline Assay & $\begin{array}{c}\text { Median }(25-75 \text { percentile }) \text { titre } \\
\text { of dipstick-positive samples }\end{array}$ & $\begin{array}{c}\text { Median }(25-75 \text { percentile }) \text { titre } \\
\text { of dipstick-negative samples }\end{array}$ & p value \\
\hline SAT & $2560(1280-5120)$ & $320(160-640)$ & $<0.0001$ \\
SAT-DTT & $320(160-640)$ & $240(160-320)$ & $>0.05$ \\
IgM ELISA & $2560(1280-5120)$ & $60(0-160)$ & $<0.0001$ \\
IgG ELISA & $1280(400-2560)$ & $2560(1280-5120)$ & $<0.01$ \\
\hline
\end{tabular}


value significantly higher $(\mathrm{p}<0.0001)$ than the mean (60) calculated for dipstick-negative serum samples (Table 1). Although the results obtained in the $\mathrm{IgG}$ ELISA for the two groups were also significantly different, this was at a lower level $(\mathrm{p}<0.01)$ (Table 1).

The performance of the dipstick IgM was also evaluated with the sera of 10 patients without relapse and three with relapse (confirmed by blood culture) taken at periodic intervals. In the first group, the dipstick assay became negative 2-15 months after diagnosis. In the second group, samples taken after the relapse showed no evidence of $\operatorname{IgM}$ antibodies by $\operatorname{IgM}$ ELISA and were all dipstick-negative. These results confirm the findings of Pellicer et al. [15] and Ariza et al. [13], who have shown that there are high levels of specific IgM in the initial stages of the disease, that specific IgM decreases faster than $\operatorname{IgG}$ and $\operatorname{IgA}$, and that, during relapse, there is a transient increase of $\mathrm{IgG}$ and $\operatorname{IgA}$, but not of $\operatorname{IgM}$.

Mercaptans (2-mercaptoethanol or DTT) cause the cleavage of disulphide bonds of $\operatorname{IgM}$ and loss of agglutinin activity. Thus, comparison of results obtained in the absence or presence of these agents is often used to distinguish $\operatorname{IgM}$ from $\operatorname{IgG}$ activity and to differentiate between early and persistent infection in human brucellosis [1,16-18]. As the results of this work illustrate, the interpretation of this test is not so straightforward [7]. Despite the good overall correlation between dipstick IgM, SAT and SAT-DTT, and IgM ELISA, discrepant results were observed for five sera (Table 2). These five sera were positive by RB, SAT, DGD, CIEP and IgG ELISA. In four sera (nos. 1-4) the dipstick assay and IgM ELISA were positive, but there was no reduction at all (nos. 3 and 4) or no significant reduction (nos. 1 and 2) in SAT titres in the presence of DTT. Significantly, these four sera con- tained high levels of IgG (Table 2). Therefore, it seems that high levels of agglutinating IgG mask any decrease in IgM activity and that, in such cases, a negative result in the SAT-DTT cannot be interpreted as absence of IgM. Accordingly, the IgM ELISA and the dipstick assay are more reliable tests.

A different kind of problem in the interpretation of the SAT-DTT is illustrated by the results obtained with serum no. 5 (Table 2). This serum was negative in the dipstick assay and had a titre of only 50 in the IgM ELISA. However, DTT reduced the SAT titre by more than three dilutions (Table 2) suggesting that DTTsensitive antibodies other than $\operatorname{IgM}$ were responsible for the SAT results. To investigate this, $\operatorname{IgA}, \operatorname{IgM}$ and $\mathrm{IgG}$ antibodies were removed from the serum samples. Removal of $\mathrm{IgG}$ or $\mathrm{IgM}$ caused no reduction in the SAT titre, whereas a reduction in SAT from 2560 to 160 was observed after IgA removal. To investigate the detection of $\operatorname{IgA}$ antibodies in agglutination tests (RB and SAT) and its sensitivity to DTT, a further 75 sera from brucellosis patients were studied. Only one of these sera showed a reduction in SAT titre in the presence of DTT that was attributable to $\operatorname{IgA}$. This serum had a SAT titre of 2560 which dropped to 320 when DTT was used (Table 3). The purified IgA1 fraction was positive in the RB, had a SAT titre of 320, and gave a SAT-DTT titre of 20. The agglutinating capacity of IgA antibodies found in this study confirms the results previously described by other authors $[3,5]$ and indicates that the reduction of agglutination titre in the presence of mercaptans is not always due to the inactivation of $\operatorname{IgM}$ antibodies.

To test whether other tests can be complemented by the dispstick IgM, the DGD with S-LPS and the CIEP with soluble proteins (SP) were performed. The results of the DGD test revealed that all the dipstick-positive

Table 2. Analysis of the sera with no correlation between SAT plus SAT-DTT and dipstick assay

\begin{tabular}{|c|c|c|c|c|c|c|c|c|}
\hline \multirow{2}{*}{$\begin{array}{l}\text { Serum } \\
\text { no. }\end{array}$} & \multirow{2}{*}{$\begin{array}{l}\text { Dipstick } \\
\text { result }\end{array}$} & \multicolumn{5}{|c|}{ Titre in } & \multirow[b]{2}{*}{ DGD (LPS) } & \multirow[b]{2}{*}{ CIEP (P) } \\
\hline & & SAT & SAT-DTT & IgM ELISA & IgG ELISA & IgA ELISA & & \\
\hline 1 & $3+$ & 2560 & 1280 & 2560 & 2560 & 5120 & Positive & Positive \\
\hline 2 & $2+$ & 1280 & 640 & 640 & 5120 & 2560 & Positive & Positive \\
\hline 3 & $2+$ & 640 & 640 & 320 & 2560 & ND & Positive & Positive \\
\hline 4 & $2+$ & 640 & 640 & 320 & 5120 & ND & Positive & Positive \\
\hline 5 & Negative & 2560 & 160 & 80 & 2560 & 2560 & Positive & Positive \\
\hline
\end{tabular}

$\mathrm{ND}$, not done.

Table 3. Activity of the jacaline-purified fraction of a serum from a dipstick-negative brucellosis patient with DTTsensitive antibodies

\begin{tabular}{|c|c|c|c|c|c|c|c|c|c|}
\hline \multirow{2}{*}{\multicolumn{3}{|c|}{ Isotype $(\mathrm{mg} / 100 \mathrm{ml})$}} & \multicolumn{6}{|c|}{ Titre in } & \multirow[b]{3}{*}{$\mathrm{RB}$} \\
\hline & & & \multirow[b]{2}{*}{ SAT } & \multirow[b]{2}{*}{ SAT-DTT } & \multicolumn{3}{|c|}{ SAT after absorption with } & \multirow[b]{2}{*}{ IgM ELISA } & \\
\hline IgM & $\operatorname{IgG}$ & $\operatorname{IgA}$ & & & anti-IgM & anti-IgG & anti-IgA & & \\
\hline$<5$ & $<5$ & 120 & 320 & 20 & 320 & 320 & $<20$ & $<10$ & $4+$ \\
\hline
\end{tabular}


serum samples and all but three $(83.3 \%)$ of the dipstick-negative sera contained precipitating antibodies against LPS. All but five (88.6\%) dipstickpositive sera and all dipstick-negative sera developed precipitation lines with the SP antigen in CIEP. As antibodies to SP appear at later stages $[2,8,9]$, these results show that for diagnostic purposes the CIEP test but not the DDG complements the dipstick IgM or other tests measuring anti-S-LPS IgM. As CIEP results are obtained in $c .1 \mathrm{~h}$ and the IgM dispstick is also a quick test, the combination of these two tests represents a quick and simple procedure to assess the degree of evolution of the infection.

In summary, this study has confirmed the utility of the dipstick assay as a test for the investigation of specific IgM antibodies to the Brucella S-LPS and its complementarity with tests detecting IgG to S-LPS or tests detecting antibodies to SP. Finally, it is necessary to point out that the IgM dipstick results are expressed from 0 (negative) to $4+$. Although adequate for diagnostic purposes, this system carries some degree of subjective assessment. Observation of serum dilutions has revealed that some sera remained $\operatorname{IgM}$ dipstick-positive up to a dilution of 1 in 1600. This is a useful method to titrate $\operatorname{IgM}$, but it is clearly more cumbersome than rating of the staining intensity at the recommended single dilution of 1 in 50 .

We are grateful to I. Moriyón for helpful suggestions and critical comments on the manuscript, and to I. Martín-Subero for help with the statistical analyses. This study was supported by the Departamento de Salud del Gobierno de Navarra (Spain) (grant no. 1813). Fellowship support from the Ministerio de Asuntos Exteriores (Spain) for R.N-P. is also gratefully acknowledged.

\section{References}

1. Reddin JL, Anderson RK, Jenness R, Spink WW. Significance of $7 \mathrm{~S}$ and macroglobulin brucella agglutinins in human brucellosis. N Engl J Med 1965; 272: 1263-1268.

2. Díaz R, Maraví-Poma E, Rivero A. Comparison of counterimmunoelectrophoresis with other serological tests in the diagnosis of human brucellosis. Bull World Health Organ
1976; 53: 417-424.

3. Heremans JF, Vaerman J-P, Vaerman C. Studies on the immune globulins of human serum. II. A study of the distribution of anti-brucella and anti-diphtheria antibody activities among gamma $_{\mathrm{s}} \mathrm{s}-$, gamma $1 \mathrm{M}$ - and gamma $1 \mathrm{~A}$-globulin fractions. $J$ Immunol 1963; 91: 11-17.

4. Wilkinson PC. Immunoglobulin patterns of antibodies against brucella in man and animals. J Immunol 1996; 96: 457-463.

5. Zinneman HH, Seal US, Hall WH. Some molecular characteristics of blocking antibodies in human brucellosis. Soluble antigen-antibody complexes. IX. J Immunol 1964; 93: 993-1000.

6. Kerr WR, Payne DJH, Robertson L, Coombs RRA. Immunoglobulin class of brucella antibodies in human sera. Immunology 1967; 13: 223-225.

7. Díaz R, Moriyón I. Laboratory techniques in the diagnosis of human brucellosis. In: Young EJ, Corbel MJ (eds) Brucellosis: clinical and laboratory aspects. Boca Raton, FL, CRC Press. 1989: 73-78.

8. Laudat P, Van der Mee-Marquet N, Loulergue J, Audurier A. [Informative capacity of 8 serological tests in the diagnosis of human brucellosis.] Capacité informative de huit tests sérologuiques dans le diagnostic de la brucellose humaine. Pathol Biol 1995; 43: 754-759.

9. Goldbaum FA, Rubbi CP, Wallach JC, Miguel SE, Baldi PC, Fossati CA. Differentiation between active and inactive human brucellosis by measuring antiprotein humoral immune responses. J Clin Microbiol 1992; 30: 604-607.

10. Smits HL, Basahi MA, Díaz $\mathrm{R}$ et al. Development and evaluation of a rapid dipstick assay for serodiagnosis of acute human brucellosis. J Clin Microbiol 1999; 37: 4179-4182.

11. Morgan WJB, MacKinnon DJ, Lawson JR, Cullen GA. The rose bengal plate agglutination test in the diagnosis of brucellosis. Vet Rec 1969; 85: 636-640.

12. Renoux G, Plommet M, Philippon A. Microréactions d'agglutination et the fixation du complément pour le diagnostic des brucelloses. Ann Rech Vet 1971; 2: 263-269.

13. Ariza J, Pellicer R, Pallarés R, Foz A, Gudiol F. Specific antibody profile in human brucellosis. Clin Infect Dis 1992; 14: $131-140$.

14. Díaz-Aparicio E, Marín CM, Alonso-Urmeneta B et al. Evaluation of serological tests for diagnosis of Brucella melitensis infection of goats. J Clin Microbiol 1994; 32: 1159-1165.

15. Pellicer T, Ariza J, Foz A, Pallarés R, Gudiol F. Specific antibodies detected during relapse of human brucellosis. $J$ Infect Dis 1988; 157: 918-924.

16. Buchanan TM, Faber LC. 2-Mercaptoethanol Brucella agglutination test: usefulness for predicting recovery from brucellosis. J Clin Microbiol 1980; 11: 691-693.

17. Klein GC, Behan KA. Determination of Brucella immunoglobulin $\mathrm{G}$ agglutinating antibody titer with dithiothreitol. $J$ Clin Microbiol 1981; 14: 24-25.

18. Young EJ. Serologic diagnosis of human brucellosis: analysis of 214 cases by agglutination tests and review of the literature. Rev Infect Dis 1991; 13: 359-372. 